\section{Cambio y continuidad del liderazgo indígena en el cacicazgo y en la milicia de las misiones jesuíticas: análisis cualitativo de las listas de indios guaraníes Transition and continuity of the indigenous leadership in the kinship organization and in the militia of the jesuit missions: qualitative analysis of the name lists of guaraní indians}

Kazuhisa Takeda*
Resumen: Es bien sabida la existencia de varias organizaciones sociopolíticas en las misiones jesuítico-guaraníes. Entre ellas se encontraban el cabildo, la milicia, la congregación y el cacicazgo. Basándose en descripciones de cronistas jesuitas, los historiadores con frecuencia sostienen que la mayoría de los cargos de estas organizaciones eran ocupados por caciques con el título de Don. Sin embargo, el análisis comparativo de los padrones de indios guaraníes y los reclutamientos de soldados demuestra que en la segunda mitad del XVII se introdujo en las misiones jesuíticas una organización militar cuyo principio era fundamentalmente diferente al del cacicazgo, mientras que la mayor cantidad de los cargos militares eran ocupados por indios que no habían sido caciques. El propósito de este artículo es analizar algunos documentos que contienen listas de nombres de indios guaraníes para establecer cuál fue el rol de los caciques en el cacicazgo y en la milicia, y el cambio que experimentó su poder dentro de estas dos organizaciones que estructuraban las misiones jesuíticas del Río de la Plata. Palabras clave: guaraníes; cacique; cacicazgo.

Abstract: It is well known that there were a number of sociocultural organizations in the Jesuit-Guaraní community towns in the colonial Río de la Plata region of South America. These are referred to as misiones or reducciones, and among them we have the town council (cabildo), militia (milicia), congregation (congregación), and kinship
* JSPS Postdoctoral Fellow for Research Abroad, Tokio, Japón. Investigador visitante, Escuela de Estudios Hispanoamericanos, Sevilla, España. Investigador visitante, Museo Nacional de Etnología, Osaka, Japón. E-mail: kazuhisatakeda@hotmail.com 
organization (cacicazgo). On the basis of descriptions in Jesuit chronicles, historians in general have insisted that the Guaraní Indian chief, who was called cacique, dominated the most of official position in each organization. Yet, a comparative analysis of the names of the inhabitants of the Jesuit Missions and the indigenous soldiers, reveals that in the second half of seventeenth century, the military organization, whose fundamental structure differed totally from that of the cacicazgo was introduced in the missions, and Guarani Indians, who were not cacique, occupied most of the military positions. The purpose of this article is to analyze some documents that contain the names of Guarani Indians, in order to clarify the role of the cacique in the cacicazgo and in the milicia as well as the transition of his authority in the Jesuit Missions of the Río de la Plata.

Key words: guaraní Indians; indian chief; kinship organization.

\section{Introducción}

En el Río de la Plata bajo la dominación española, existió un conjunto de asentamientos que tuvieron el propósito de convertir a los indígenas al cristianismo, las llamadas reducciones o misiones. Particularmente, aquellos establecimientos creados por los padres de la Compañía de Jesús tuvieron fama global. Los 30 pueblos de los jesuitas tuvieron una larga historia de más del 150 años (1609-1767) y su vida comunitaria comparó con una utopía, llamando mucho la atención de los intelectuales de Europa de aquel tiempo.

Con el objetivo de lograr la adquisición de la cultura, la institución y la costumbre oriunda de Europa entre los guaraníes, los jesuitas establecieron diversas organizaciones en las reducciones, entre las cuales el cabildo, la milicia y la congregación fueron las principales ${ }^{1}$. Estas organizaciones les daban a los guaraníes influencia sociocultural, transformando fuertemente su sistema político, militar y religioso tradicional.

Por otra parte, el poder autóctono de los jefes guaraníes era útil e indispensable para supervisar numerosos habitantes de los pueblos ${ }^{2}$. Los jesuitas autorizaron ese poder por medio de varias instituciones españolas tales como las leyes indianas y las visitas de los gobernadores del Paraguay y del Río de la Plata. Los jefes guaraníes se llamaban caciques y sus poderes vigentes sobre sus vasallos se denominaban cacicazgos. Sobre el proceso histórico de inventar el linaje aristocrático de los caciques guaraníes, tienen valor los estudios

\footnotetext{
${ }^{1}$ Sobre el cabildo, véase (Díaz de Zappia, 2003; Wilde 2009, especialmente después de la expulsión de los jesuitas). Los estudios de (Kern, 1982; Avellaneda, 2005; Avellaneda y Quarleri, 2007, Svriz Wucherer 2011a, 2011b, 2011c) tratan del aspecto geopolítico de las misiones jesuíticoguaraníes y las milicias. Pablo Hernández y Guillermo Furlong nos han dado una descripción breve sobre la congregación (Hernández, 1913, vol. 1, pp. 309-310; Furlong, 1962, pp. 281-282).

${ }^{2}$ La teoría establecida por Branislava Susnik sobre la organización autóctona de los guaraníes ha sido la más influyente (Susnik, 1970; 1979-80).
} 
de Guillermo Wilde en los que sugiere que la autorización de los poderes de los caciques a la manera de costumbre española se vinculaba con la política de incorporación de los indígenas al régimen colonial de imperio español. Entretanto, los caciques guaraníes utilizaban esta autorización introducida por los españoles para fortalecer sus poderes dentro del espacio reduccional (Wilde, 2006; 2009).

El tema central de este artículo es entender el rol de los caciques en el cacicazgo y en la milicia y el proceso histórico de surgimiento de una milicia profesional en las misiones jesuítico guaraníes. En la primera etapa, el poder de los caciques estaba orientado a la dirección de los seguidores entre diversos asuntos. Algunos manuscritos guardados en el Archivo Nacional de Chile sobre las funciones de un cacique resultan de gran interés. Se trata de los manuscritos referidos al otorgamiento de cargos militares por parte de los gobernadores españoles a los caciques guaraníes. Además del trabajo en campo de batalla, los caciques nombrados a capitán tenían el rol de castigar a los culpables o de premiar a los de buena conducta para imponer la disciplina en la vida diaria de los pueblos misioneros (Salínas, 2006). No obstante, debido al tiempo transcurrido y a la situación geopolítica de las reducciones jesuíticas, los caciques guaraníes iban perdiendo sus múltiples presencias dentro del espacio misional.

La transformación del poder de los caciques y de la estructura de organización interna de las misiones jesuíticas a largo plazo no resulta clara si nos basamos en el simple análisis de los documentos descriptivos. Las cartas, los libros, los ensayos, los informes y los memoriales presentan descripciones generales sobre esos temas, pero tendríamos que consultar otro tipo de documentos para recuperar los mayores detalles.

La propuesta de este artículo es utilizar listas de nombres y de apellidos de indios guaraníes que aparecen a lo largo del tiempo. Este tipo de documento enumera varios datos minuciosos que a través del cálculo y la clasificación desde un punto de vista específico o de la comparación con otro tipo de documentos, revela resultados sumamente interesantes ${ }^{3}$.

Existen algunos estudios basados en el análisis de las listas. Sin embargo, se trata de estudios de historia demográfica de las misiones jesuítico-guaraníes cuyo objetivo es el análisis dinámico de la cantidad de los habitantes (Jackson, 2004a; 2004b; 2008a; 2008b; Maeder, 1975; 1989; Maeder y Bolsi, 1974; 1976; 1989; Maeder y Livi-Bacci, 2004). Branislava Susnik, quien argumentó la importancia de los padrones como fuente documental para el análisis dinámico de los fugitivos guaraníes, enfocó su punto de vista analítico para los 13 pueblos

\footnotetext{
${ }^{3}$ Guillermo Wilde ha sostenido la importancia de análisis de los padrones para la aclaración de la evolución de los cacicazgos a lo largo del tiempo (Wilde, 2009, p. 407).
}

Tellus, ano 12, n. 23, jul./dez. 2012 
de las misiones bajo jurisdicción paraguaya, en especial de la expulsión de los jesuitas (Susnik, 1966). El interés de este artículo, por contraste, es analizar las listas para aclarar el papel de los caciques en el cacicazgo y en la milicia y el cambio cronológico de su presencia en la organización de cada una dentro del espacio misional.

Para ello, se utilizan algunas listas de nombres de indios guaraníes elaboradas en ocasión de la visita de los gobernadores españoles a los pueblos indígenas, determinando el número de tributarios y de soldados guaraníes enviados a distintos campos de batalla de la región rioplatense por orden de los mismos gobernadores. Como se verá, el análisis de estos documentos conteniendo listas permite aclarar la diferencia fundamental que existió en las misiones jesuíticas entre el principio de organización del cacicazgo, por un lado, y el de la milicia, por otro.

\section{Los caciques y el cacicazgo en las misiones jesuíticas}

\subsection{El rol de los caciques}

Los caciques tuvieron un papel importante en la formación de la vivienda no solamente en la época precolombina sino en el período jesuítico. Un cacique formaba una casa y vivía con sus vasallos en ella. Muchos jesuitas describieron que esta manera de vida se encontraba en la base. Respecto al modo autóctono de vivir, podemos consultar una descripción escrita en diciembre de 1620 por un jesuita anónimo:

[Los guaraníes] Habitan en casas bien hechas armadas en çima de buenos horcones cubiertas de paja, algunas tienen ocho y diez horcones y otras mas o menos conforme el cazique tiene los basallos porque todos suelen vivir en una casa. no tiene division alguna toda la casa, esta esenta (sic) de manera que desde el prinçipio se vee el fin: de horcon a horcon es un rancho y en casa uno habitan dos familias una a una banda y otra a otra y el fuego de estambos (sic) esta en medio: duermen en unas redes que los españoles llaman hamacas las quales atan en unos palos que quando haçen las casas dejan a proposito y estan tan juntas y entre tejidas las hamacas de noche que en ninguna manera se puede andar por la casa (Anónimo, 1951, p. 166-167).

La estructura de este tipo de viviendas sobreviviría al menos unas décadas, durante el comienzo de la vida comunitaria en las reducciones. Por ejemplo, la Carta Anua de los años 1626-1627 permite ver la similitud de las estructuras físicas de las casas de los guaraníes antes y después del contacto:

[...] cada una (i lo mismo usan en todo el Paraguay) es [casa] una gran pieza donde vive el cacique con toda su parcialidad, o vasallos que suelen ser veinte, treinta, quarenta, i a veces mas de cien familias; segun la 
calidad del cacique: ní tienen otra division, o apartamiento estas casas, que unos pilares que corren por medio de edificio a trechos, i sirven de sustentar la cumbre, i de señalar el termino de la vivienda de casa familia, que es el espacio que ay entre uno i otro pilar, una de esta vanda, i otra de aquella (Mastrilli Durán, 1929, p. 362-363).

Según los estudios antropológicos, varias familias autóctonas guaraníes formaban una casa que se llama maloca. Una maloca estaba dirigida por un cacique. El número de personas encabezado por este jefe era muy variado (Necker, 1990, p. 27; Roulet, 1992, p. 166). Al establecer los nuevos asentamientos, los jesuitas aprovechaban el poder de los caciques para organizar la vivienda dentro del espacio misional, de la misma manera que la antigua costumbre guaraní. Es decir, se componía un pueblo misionero de un conjunto de distintas familias.

Además de formar vivienda, se utilizaba el poder de los caciques para los trabajos colectivos. A mediados del siglo XVII, el padre jesuita Pedro Mola ordenó a los indios dedicarse a una obra pública, pero ellos no le obedecieron. Entonces, un indio principal le aconsejó al padre pedirles el mismo trabajo mediante los caciques y finalmente de este modo los guaraníes aceptaron la petición del padre Mola 4 .

La utilización del poder de los caciques para dirigir a los guaraníes "plebeyos" era aún una modalidad convencional en el siglo XVIII. En los memoriales de los Padres Provinciales de la Provincia Jesuítica del Paraguay a los misioneros, se determinaba el modo de hacer trabajar a los guaraníes. Por ejemplo, un memorial enviado al pueblo de San Miguel fechado en 28 de junio de 1714 ordenaba a los guaraníes reconstruir sus viviendas bajo la dirección de sus caciques 5 . Otro memorial escrito en 1 de julio de 1714 para el pueblo de San Lorenzo aconsejaba a los misioneros que los caciques dirigiesen a sus vasallos en el cultivo del campo ${ }^{6}$.

Podemos hacer un cálculo aproximado del número de los caciques en un pueblo a través del análisis de los padrones elaborados en ocasión de las visitas de los gobernadores españoles. Trataremos dos visitas, una de la década de cincuenta del siglo XVII y otra del comienzo del siglo XVIII.

En 1657 el gobernador del Paraguay Juan Blázquez de Valverde recibió un informe del número de los caciques en cada pueblo. En aquel tiempo existieron 19 pueblos y el total de los caciques era 581. El promedio de cada

\footnotetext{
4 "Información en favor de los caciques de la nación guaraní en que suplica haber habido siempre caciques," AGN IX 6-9-3.

5 “Memorial del P. Provincial Luis de la Roca en la visita de 28 de junio de 1714 para esta doctrina de San Miguel," AGN IX 6-9-5.

6 "Memorial del P. Provincial Luis de la Roca en esta visita de 1 de julio de 1714 para esta doctrina de San Lorenzo," AGN IX 6-9-5.
}

Tellus, ano 12, n. 23, jul./dez. 2012 
pueblo era de 30 caciques (Jesuitas, 1915, p. 512-515). En 1715 el gobernador del Paraguay Juan Gregorio Bazán de Pedraza visitó todas las reducciones para evaluar el número de tributarios. El total de los pueblos en aquel tiempo era casi 30, aunque faltan algunos padrones de ciertos pueblos. A pesar de esto, podemos saber que vivieron 368 caciques en 10 pueblos y el promedio de éstos era 36 (Bazán de Pedraza, 1946, p. 10-31). Estos dos promedios corresponden a una descripción del padre José Cardiel en la segunda mitad del siglo XVIII. Cardiel dice que en cada pueblo suele haber 20, 30, 40 caciques (Cardiel, 1913, p. 557). Pero en realidad el número de los caciques de cada pueblo podía variar según la envergadura del pueblo u otros factores. En el año 1657, por ejemplo, el pueblo de Itapúa tenía 55 caciques, mientras el número de los caciques en el pueblo de Mártires era solamente 15. Otro ejemplo muestra que en el año de 1715 Loreto tenía más de 80 caciques, mientras que Trinidad tenía solamente 15.

Tabla 1 - Número de los caciques guaraníes en las misiones jesuíticas

\begin{tabular}{|l|c|c|}
\hline \multicolumn{1}{|c|}{ Nombre del pueblo } & Año 1657 & Año 1715 \\
\hline San Carlos & 24 & s.d. \\
\hline San Nicolás & 33 & s.d. \\
\hline Apóstoles & 30 & s.d. \\
\hline Concepción & 42 & s.d. \\
\hline San Miguel & 17 & s.d. \\
\hline Mártires & 15 & s.d. \\
\hline Santa María la Mayor & 37 & s.d. \\
\hline San Francisco & 25 & s.d. \\
\hline Santo Tomñe & 37 & s.d. \\
\hline Asunción de Nuestra Señora del Mbororé & 18 & s.d. \\
\hline Yapeyú & 34 & s.d. \\
\hline Itapúa & 55 & s.d. \\
\hline Candelaria & 20 & 27 \\
\hline San Cosme y Damián & 15 & s.d. \\
\hline Santa Ana & 29 & 41 \\
\hline Loreto & 44 & 80 \\
\hline San Ignacio Yabebirí (San Ignacio Miní) & 34 & 65 \\
\hline San José & 50 & 33 \\
\hline Corpus & 22 & 38 \\
\hline Jesús & s.d. & 28 \\
\hline Santiago & s.d. & 22 \\
\hline Nuestra Señora de Fe & s.d. & 19 \\
\hline Trinidad & s.d. & 15 \\
\hline total & 581 & 368 \\
\hline
\end{tabular}

Fuente: Jesuitas, 1915, p. 512-515; Bazán de Pedraza, 1946, p. 10-31. 
Además de la diferencia del número de los caciques en cada pueblo, el número de los vasallos de un cacique era también muy variado. Veremos un resultado del análisis del padrón de San Ignacio Miní fechado en 21 de septiembre de 1715, elaborado con motivo de la visita del Gobernador del Paraguay Bazán de Pedraza. Este padrón es la lista de los nombres de los habitantes del pueblo. Los guaraníes pertenecían a un grupo denominado 'parcialidad'7 dirigida por un cacique. En el padrón, todos los caciques se presentaban como 'cacique principal', indiferentemente del número de los vasallos de cada uno. En primer lugar, se dan el nombre y el apellido del cacique, y luego seguían los nombres de su mujer, hijos e hijas, mencionando solamente la edad de los varones. Al final de la lista de nombres de cada familia había una línea horizontal que marcaba la división con respecto a la siguiente familia. En aquel tiempo, vivieron en el pueblo 90 caciques (89 caciques y una cacica). La población total era de 2.803 personas y el número de familias era 708, con un promedio de 4 personas por familia.

A partir del análisis del padrón de San Ignacio Miní, podemos extraer las siguientes conclusiones. El tipo de cacique más común, de los cuales había 63 casos, dirigía un cacicazgo compuesto por entre 1 y 40 vasallos. Unos 16 caciques controlaban cacicazgos compuestos por entre 41 y 60 súbditos y había 2 caciques que formaban cacicazgos de más de 100 vasallos, pero esto era muy excepcional. Un pueblo era un conjunto de cacicazgos, pero según la envergadura de cada uno, el poder de los caciques podía ser completamente diferente.

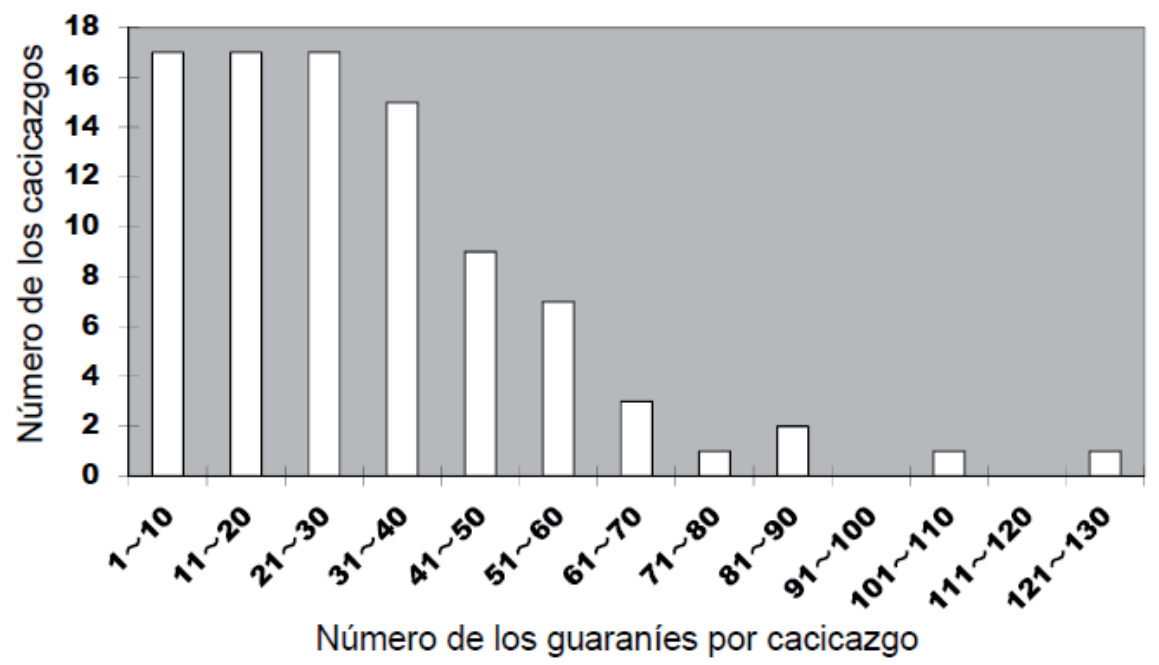

Gráfico 1 - Cacicazgos en el pueblo de San Ignacio Miní (1715)

Fuente: "Padrón del pueblo de San Ignacio del Yabebirí (i.e, San Ignacio Miní)", San Ignacio Miní, 21 de septiembre de 1715, AGN IX 6-9-5, f. 572-594.

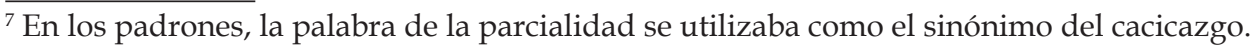




\subsection{El status social de los caciques}

Hasta aquí hemos constatado la importancia de los caciques para mantener el cacicazgo de las misiones jesuíticas. Ahora bien, ¿qué tipo de poder o de status social fueron otorgados a los caciques en la vida comunitaria con los jesuitas? El padre José Cardiel nos dejó la siguiente respuesta sobre esta cuestión.

Los caciques son nobles por declaración real, y tienen el título de Don en señal de nobleza. Cada uno de ellos tiene treinta, cuarenta o más vasallos, quienes acompañan a su cacique a los oficios comunes, le ayudan en sus ocupaciones particulares y le guardan respeto; pero no reciben salario alguno. Ni la nobleza los exime del trabajo mecánico; al contrario, tienen a gala el ser carpinteros, escultores, pintores, o ejercitar cualquier otro oficio (Cardiel, 1918, p. 473-474).

Además, basándose en las descripciones de cronistas jesuitas, los caciques estaban a cargo de diversas organizaciones como el cacicazgo, la milicia, el cabildo y otros tipos. Los puestos importantes de cada organización correspondían a una posición honorífica en los pueblos misioneros. Los hijos de los caciques podían aprender a leer, escribir y cantar en la escuela del pueblo. El propósito de esta educación era criar ayudantes para la administración de los pueblos y aquellos que habían terminado la carrera educativa pasaban a una "clase aristócrata" (Cardiel, 1913, p. 557; Cardiel, 1949, p. 140; Peramás, 1946, p. 72; Sepp, 1974, p. 183).

Según estas explicaciones dadas por los jesuitas, podríamos decir que las posiciones importantes en las reducciones eran ocupadas por los caciques. Igualmente en el caso de las milicias, los cargos serían siempre ocupados por los caciques que habían recibido el título de Don. Sin embargo, el análisis de la lista de los reclutamientos de soldados guaraníes derriba este tipo de suposición.

\section{Génesis y cambio de la estructura de la organización militar}

\subsection{Comienzo y desarrollo de la organización militar}

En la sociedad antigua guaraní, los caciques dirigían sus vasallos en el campo de batalla contra los enemigos (Roulet, 1993, p. 59-60, 81-82). El padre José Guevara nos describe el modo de elección de un líder militar entre los candidatos así:

Antes de declarar guerra precede junta de los principales, de cuyo acuerdo pende la última resolución. Júntase el congreso en la toldería de alguno de los caciques, [...] Al decreto de la guerra se sigue la elección de 
jefe, que dirija la facción con acierto y gloria de la nación. Suele ser muy disputada, y no es fácil concordar las partes, porque todos ambicionan el honor de capitán general del ejército (Guevara, 1836, p. 11).

En el comienzo del siglo XVII, cuando los jesuitas empezaron a fundar las primeras reducciones en el Río de la Plata, intentaron nombrar algunos caciques como "capitanes generales" y otros cargos militares a fin de pacificar a los indios rebeldes en la región del río Paraná. No obstante, la mayoría de los caciques intentaron mostrar sus destrezas en el manejo de las armas de guerra y quisieron dirigir a sus súbditos haciendo ostentación de su poder (Lozano, 1755, p. 202-205). Este episodio nos muestra la dificultad de los jesuitas para seleccionar a los jefes militares entre los líderes guaraníes. Podemos decir que tanto en la época precolombina como en el comienzo del período jesuítico los caciques eran los jefes militares y con frecuencia se encargaron de los puestos de guerra.

La entrega de los cargos militares a los caciques era normal no solamente en el comienzo del siglo XVII sino también en la primera mitad del mismo siglo. En los años de 1629, 1639, 1640 y 1656 los gobernadores españoles otorgaron cargos militares a 14 guaraníes, 13 de los cuales tenían título de Don. Con respecto a Ayeo, se escribió como el "primer cacique que comienzo (i.e., comenzó) a reducir la gente del Tape para la reducción de Santo Tomé."

Tabla 2 - Otorgamiento de cargos militares a los guaraníes con título de Don

\begin{tabular}{|l|l|c|}
\hline \multicolumn{1}{|c|}{ nombre y apellido } & \multicolumn{1}{c|}{ cargo militar } & fecha \\
\hline Ayeo & capitán & $1 / 8 / 1629$ \\
\hline D. Antón Arambare & maestre de campo & $1 / 2 / 1639$ \\
\hline D. Nicolás Ñeenguiru & capitán insolidium & $18 / 12 / 1640$ \\
\hline D. Francisco Bairoba & capitán & idem \\
\hline D. Antonio Guaracica & capitán & idem \\
\hline D. Teodoro Itambay & capitán & idem \\
\hline D. Francisco Abie & capitán & idem \\
\hline D. Roque Guiracazu & capitán de guerra & 20/4/1656 \\
\hline D. Simon Aycoaybe & alférez & idem \\
\hline D. Pedro Euocoye & capitán & idem \\
\hline D. Francisco Guirayague & capitán & idem \\
\hline D. Gaspar Añangare & capitán & $20 / 5 / 1656$ \\
\hline D. Mathias Veramini & capitán & capitán de infantería \\
\hline D. Juan Birayu & & idemo
\end{tabular}

Fuente: Documentos Varios: gobierno, hacienda, particulares, etc., 1571-1633, Tomo 1, AGN IX 47-7-2; Documentos Varios: gobierno, hacienda, particulares, etc., 1634-1647, Tomo 2, AGN IX 47-7-3; Documentos Varios: gobierno, hacienda, particulares, etc., 1654-1657, Tomo 4, AGN IX 47-7-5; Salínas, 2006, p. 270-276. 
¿Con qué motivo se entregaron los cargos militares a algunos caciques en estos períodos? Acaso los gobernadores españoles querían responder al ataque de enemigos tales como los portugueses y los indios rebeldes. En la primera mitad del siglo XVII, los portugueses organizaron una expedición bandeirante para cautivar a los indios y venderlos a los cañaverales de azúcar en el nordeste del Brasil. Las expediciones de los bandeirantes estaban compuesta por los portugueses que vivían en San Paulo y que organizaban milicias con los indios amigos para explorar el interior, lo que contribuyó a la formación territorial del estado brasilero actual (Carvallo, 1980, p. 36-40; Mörner, 1953, p. 87, 103). O sea, durante la primera mitad del siglo XVII podríamos decir que los guaraníes tuvieron que armarse para contraatacar a los portugueses y fueron los caciques con el título de Don quienes dirigieron a sus vasallos en el campo de batalla.

Sin embargo, después del año de 1641, la organización militar de las misiones jesuíticas comenzó a tener un papel importante desde el punto de vista geopolítico para la Corona española. Este mismo año tuvo lugar la batalla del Mbororé contra los bandeirantes y las milicias guaraníes consiguieron una victoria dramática. Esta victoria estimuló al Rey de España Felipe IV a anunciar un plan de defensa de su territorio, el que decidió por cédula real el 21 de noviembre de 1642, aprovechando a las milicias guaraníes ${ }^{8}$. En vez del servicio militar, los jesuitas pudieron recibir cierta cantidad de las cédulas reales favorables para la administración de las reducciones 9 .

Desde la segunda mitad del siglo XVII hasta el comienzo del siglo XVIII, las milicias guaraníes fueron sistematizadas y se establecieron diversos cargos. Por ejemplo, el padre Antonio Sepp escribe:

Cada pueblo pone, al menos, cuatro regimientos en pie de guerra [...] y cada regimiento tiene sus capitanes, sargentos primeros, cabos, oficiales adjuntos, piqueros, alabarderos, mosqueteros, tiradores de lazo, arqueros, gente armada de escudos y mazas, exploradores etcétera (Sepp, 1974, p. 187-188).

En el mismo período, los sucesivos Padres Provinciales de la Provincia Jesuítica del Paraguay dieron diversas instrucciones militares a los pueblos misioneros. La orden del padre Provincial Diego Francisco Altamirano, fechada en 18 de enero de 1680 es una de las más destacables en la medida que da una imagen de las milicias bien organizadas utilizando el sistema de España:

El ejercicio de las armas hoy más necesario, cuanto por varias partes más nos cercan los enemigos; por tanto, todos los domingos del año habrá algún ejercicio de tirar arcabuces con bala, de las ondas, con piedras y de los arcos, con flechas y un día cada mes alarde general conservando

8 "Cédula Real," Zaragoza, 21 de noviembre de 1642 (Hernández, 1913, v. 1, p. 525-526).

9 “Cédula Real, 1643, 1647, 1649, 1661, 1679," (Hernández, 1913, v.1, p. 513-524). 
las compañías con sus capitanes y cabos de guerra en cada una y un sargento mayor y un maestre de campo en cada pueblo [...] los oficiales de milicia serán siempre los más valerosos, y porque se estimen los oficios irán subiendo a ellos por sus grados según merecieren por su valor, y les obedecerán sus soldados según se practica en la milicia española. ${ }^{10}$

Sin embargo, los documentos descriptivos producidos por los jesuitas no nos dan una idea clara de la estructura interna de las milicias. Para esclarecer esta cuestión, es muy importante el análisis de las listas de los nombres de los soldados, ya que pone de manifiesto una gran diferencia entre la organización de los ejércitos guaraníes al comienzo siglo XVII y la que corresponde al siglo XVIII.

\subsection{Análisis de las listas de los reclutamientos de soldados}

El 21 de marzo de 1761, el gobernador del Río de la Plata Pedro de Cevallos mandó a todas las reducciones a preparar la lista del número de los soldados guaraníes, de las armas del fuego, de los caballos, de las flechas, y de las lanzas. El propósito de este mandamiento sería reclutar los soldados necesarios para la ocupación de Colonia del Sacramento durante 1762-63 (Carbonell, 1992, p. 463). Quisiéramos tratar acerca del número de los soldados y de las compañías de cada reducción. En las listas de reclutamiento de los soldados, se puede observar que una compañía estaba compuesta por 50 soldados.

Tabla 3 - Número de los soldados y de las compañías de misiones jesuíticas (1761)

\begin{tabular}{|l|c|c|c|}
\hline $\begin{array}{c}\text { Nombre de las } \\
\text { reducciones }\end{array}$ & $\begin{array}{c}\text { Número de los } \\
\text { soldados (A) }\end{array}$ & $\begin{array}{c}\text { Número de la } \\
\text { compañía (B) }\end{array}$ & $\begin{array}{c}\text { Cifra media } \\
(\mathrm{A} \div \mathrm{B})\end{array}$ \\
\hline Santa Ana & 1050 & 21 & 50 \\
\hline San Miguel & 490 & s.d. & 56.9 \\
\hline Loreto & 854 & 15 & 77.5 \\
\hline San José & 310 & 4 & \\
\hline Concepción & s.d. & 8 & \\
\hline San Juan & 29 & s.d. & \\
\hline San Carlos & s.d. & 8 & \\
\hline Santo Tomé & 400 & 5 & \\
\hline San Borja & s.d. & 5 & \\
\hline San Ignacio Miní & s.d. & & \\
\hline
\end{tabular}

10 "Cartas de los PP. Generales de la Compañía de Jesús y de varios Provinciales sobre las Misiones del Paraguay, 16 de julio de 1623 a 19 de septiembre de 1754,".BNE, MSS. 6976.

Tellus, ano 12, n. 23, jul./dez. 2012 


\begin{tabular}{|l|c|c|c|}
\hline $\begin{array}{c}\text { Nombre de las } \\
\text { reducciones }\end{array}$ & $\begin{array}{c}\text { Número de los } \\
\text { soldados (A) }\end{array}$ & $\begin{array}{c}\text { Número de la } \\
\text { compañía (B) }\end{array}$ & $\begin{array}{c}\text { Cifra media } \\
(\mathrm{A} \div \mathrm{B})\end{array}$ \\
\hline Santa Rosa & 642 & 12 & 53.5 \\
\hline San Luis & 30 & s.d. & \\
\hline San Lorenzo & 32 & s.d. & \\
\hline Santo Ángel & s.d. & 1 & 50 \\
\hline Yapeyú & 300 & 6 & 58 \\
\hline San Nicolás & 87 & una y media & \\
\hline San Javier & 100 & 6 & 50 \\
\hline Apóstoles & ilegible & 6 & \\
\hline San Cosme y Damián & 100 & s.d. & \\
\hline Trinidad & ilegible & 14 & 50 \\
\hline Corpus & 700 & s.d. & \\
\hline Santiago & 100 & ilegible & \\
\hline Jesús & s.d. & 12 & 50 \\
\hline Candelaria & 600 & \multicolumn{2}{|c|}{. }
\end{tabular}

Fuente: "Carta del Padre Enis y notas oficiales de los corregidores de las Misiones sobre alistamiento de sus milicias y reseña de sus compañías, dirigidas a D. Pedro de Cevallos, con una instrucción sobre la organización militar por distritos, 1761," Museo Mitre, Armario B, Cajón 18, Núm. de Piezas 27, Núm. de Orden, 32.

En la segunda mitad de siglo XVIII, este número de 50 sería el principio para organizarse una compañía militar en todas las reducciones. Por ejemplo, en el caso del pueblo de Concepción, la lista solamente dice que existían 8 compañías, pero la misma lista menciona que cada compañía estaba compuesta por 50 soldados. El pueblo de San Carlos tenía 4 compañías oriundas de San Luis y asimismo cada compañía estaba compuesta por 50 soldados.

Este tipo de principio de organización militar de la segunda mitad del siglo XVIII es fundamentalmente diferente al de las milicias basadas en el cacicazgo del siglo XVII. Como hemos mencionado, cada cacicazgo estaba compuesto por 25, 30, o 100 guaraníes. O sea, la escala de cada uno tenía gran diferencia entre ellos. Por contraste, en el siglo XVIII cada compañía de las milicias estaba casi estrictamente compuesta por 50 soldados. En otras palabras, la organización militar de este período había llegado a estar basada en un principio muy distinto al del cacicazgo, organización básica en la vida cotidiana de las misiones jesuíticas.

Existen tres listas probablemente escritas en la segunda mitad del siglo XVIII y cada lista muestra la estructura de una compañía. Estas tres listas mencionan tanto el nombre de un capitán guaraní como su título. En primer lugar, se escriben los oficiales militares y luego siguen otros como "soldados." En cada lista hay algunas variedades en el número de los oficiales y el de los soldados. No obstante, las tres compañías están compuestas por 50 guaraníes. 


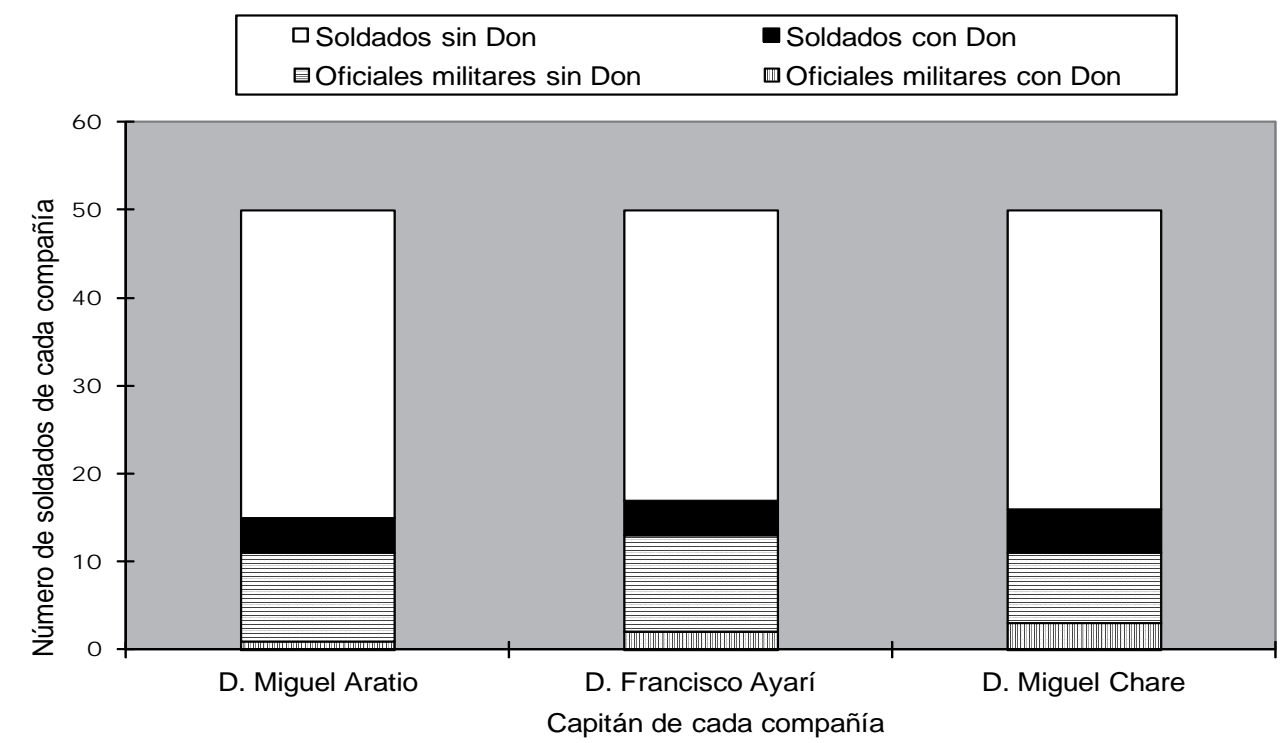

Gráfico 2 - Estructura de una compañía de milicias guaraníes (segunda mitad del siglo XVIII)

Fuente: "Pie de lista de la compañía del capitán D. Miguel Aratio"; "Pie de lista de la compañía del capitán D. Francisco Ayarí"; "Pie de lista de la compañía del capitán D. Miguel Chare," AGN IX 7-1-1.

Lo más interesante en estas tres listas es que la mayoría de los que habían tenido cargos militares eran guaraníes sin título de Don. Aún más, algunos que habían recibido el título de Don eran clasificados como soldados. Como hemos visto, hasta la mitad del siglo XVII, los cargos militares estaban ocupados por los que habían recibido el título de Don bajo el nombre de gobernador español. Sin embargo, en la segunda mitad del siglo XVIII, las listas muestran que generalmente los guaraníes sin vínculo con la "sangre azul" se encargaban de los puestos militares. Además, llama la atención el hecho de que cada compañía estaba compuesta por el mismo número de hombres, 50 guaraníes. Cabría suponer que esta manera de organizar las milicias fue una prueba practicada en varias instrucciones militares de los jesuitas Provinciales a lo largo del tiempo.

Estas evidencias indican un cambio grande en el vínculo entre el cacicazgo y la milicia. En la vida cotidiana de las reducciones jesuíticas, el cacicazgo era la organización social básica de asociación humana. Cada cacicazgo estaba dirigido por un cacique y su envergadura era muy distinta. Asimismo, el cacicazgo se aplicaba a la guerra y constituía un elemento básico de la milicia hasta la mitad del siglo XVII. En este caso, los caciques a quienes se habían otorgado cargos militares eran quienes dirigían a sus vasallos en el campo 
de batalla. Pero, en la segunda mitad del siglo XVIII, las milicias guaraníes estarían organizadas según un principio diferente del cacicazgo. De hecho, durante el período jesuítico tardío, el estado de que los puestos militares estaban ocupados por hombres que no eran caciques estaría normal.

Esta situación implicaría el reemplazo del elemento consanguíneo por el de la capacitación en la formación de los cargos militares. Con el transcurso del tiempo, los caciques envejecían y este envejecimiento les hacía difícil dedicarse a la guerra. En el momento en que debía ocurrir el reemplazo de los cargos, es posible que los caciques dejasen de ser sucedidos por sus hijos, tal vez porque algunos de ellos eran ineptos para la guerra, transformándose el arte militar en un elemento decisivo para tomar las posiciones importantes. Los jesuitas Provinciales emitían una serie de instrucciones relacionadas con las milicias tales como los ejercicios militares regulares y el otorgamiento de los premios a los que tienen mucha capacidad para cumplir los servicios militares mandados por la Corona española ${ }^{11}$. Las frecuentes órdenes de los gobernadores españoles atribuirían gran valor a los más destacados militarmente, subestimándose gradualmente el alto linaje de los caciques. Esta tendencia acabaría provocando la marginación de líderes autóctonos de los guaraníes en los cargos militares.

\subsection{Los factores del cambio de estructura de la organización militar}

¿En qué momento ocurrió la exclusión de los caciques desde los cargos militares? En 1680, el gobernador del Río de la Plata ordenó a los jesuitas despachar 3.000 guaraníes para ocupar la Colonia del Sacramento en la desembocadura del Río de la Plata. Ese mismo año los portugueses fundaron una base militar en el territorio de la Corona española. Para poder intervenir esta fundación sin ninguna autorización oficial, la Corona ordenó al gobernador del Río de la Plata ocupar la Colonia del Sacramento. El gobernador otorgó entonces varios cargos militares a los guaraníes: capitán de infantería, capitán de caballo, alférez, ayudante, sargento, sargento mayor, teniente de maestre de campo, maestre de campo. Existen unas certificaciones de cargos militares relacionadas con 15 reducciones. Solamente en el caso de San Carlos, los caciques con título de Don ocupaban la mayoría de cargos. No obstante, en las otras 14 reducciones, la mayor parte de los puestos estaba ocupada no caciques.

11 “Cartas de los PP. Generales de la Compañía de Jesús y de varios Provinciales sobre las Misiones del Paraguay, 16 de julio de 1623 a 19 de septiembre de 1754,".BNE, MSS. 6976; Bernardo Ibáñez de Echavarrí, El Reyno Jesuitico del Paraguay, apéndice documental, BCNSE. Podemos consultar este manuscrito a la página siguiente: http://www.jlnarvaja.com.ar/ falkner/Echevarria/ech-home.html 


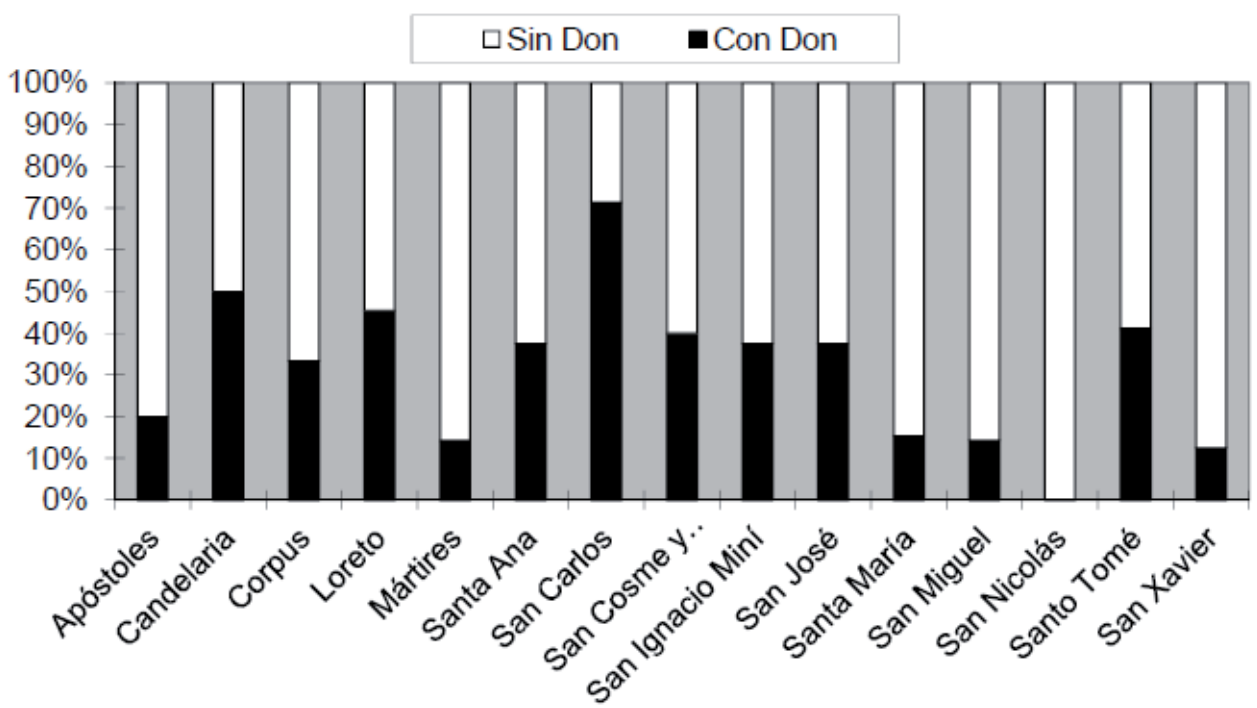

Gráfico 3 - Los guaraníes con/ sin título de Don en los cargos militares (1680) Fuente: Documentos Varios: gobierno, hacienda, particulares, etc., 1680, Tomo 12, AGN IX 47-713; Documentos Varios: gobierno, hacienda, particulares, etc., 1680, Tomo 13, AGN IX 47-7-14; Documentos Varios: gobierno, hacienda, particulares, etc., 1680-1681, Tomo 14, AGN IX 47-7-15.

En 20 de enero de 1680, antes de marcha militar para la ocupación de la Colonia, el Padre Provincial Diego Francisco Altamirano anunció una instrucción acerca de la estructura de cada compañía militar. Esta instrucción menciona claramente el número uniforme de 50 o 100 para formar una compañía:

[...] cada compañía de a caballo a de ser 50 y otros tantos tendrá la de pedreros; las demás de infantería serán de 100; en ellas se alistarán todos los capaces de tomar armas y se procurará que cada soldado sepa usar de todas las armas $[\ldots] .^{12}$

Esta instrucción llegó literalmente a la mano de los misioneros quien vivían con los guaraníes. En 28 de febrero de 1680, obedeciendo la orden del Padre Provincial, el Padre Superior Cristóbal Altamirano envió la carta siguiente a todos los pueblos misioneros:

De cada 100 indios sea de hacer una compañia de a pie con su capitán, alférez, 2 sargentos, cabo de guerra con su bandera que podrá ser de lienzo pintado o lo que tuvieren. De las compañía de a caballo constará cada una de 50 soldados son su capitán y teniente, estandarte, clarín, chirimía o corneta. ${ }^{13}$

${ }_{12}$ “Cartas de los PP. Generales de la Compañía de Jesús y de varios Provinciales sobre las Misiones del Paraguay, 16 de julio de 1623 a 19 de septiembre de 1754,".BNE, MSS. 6976.

13 “Orden del P. Cristóbal Altamirano a los padres misioneros, Candelaria, 28 de febrero de 1680," AGI Charcas 260. 
El alto número de 3.000 guaraníes enviados en ocasión de la ocupación de la Colonia del Sacramento es un punto importante para considerar la causa de transformación del poder de los caciques. Antes de 1680, el número de los guaraníes enviados al servicio militar era siempre inferior a 1.000, pero a partir de 1680, se despacharon miles de guaraníes a distintos campos de batalla. Para movilizar tal cantidad de soldados, los jesuitas tuvieron que establecer milicias profesionales con un modelo de organización totalmente diferente al del cacicazgo.

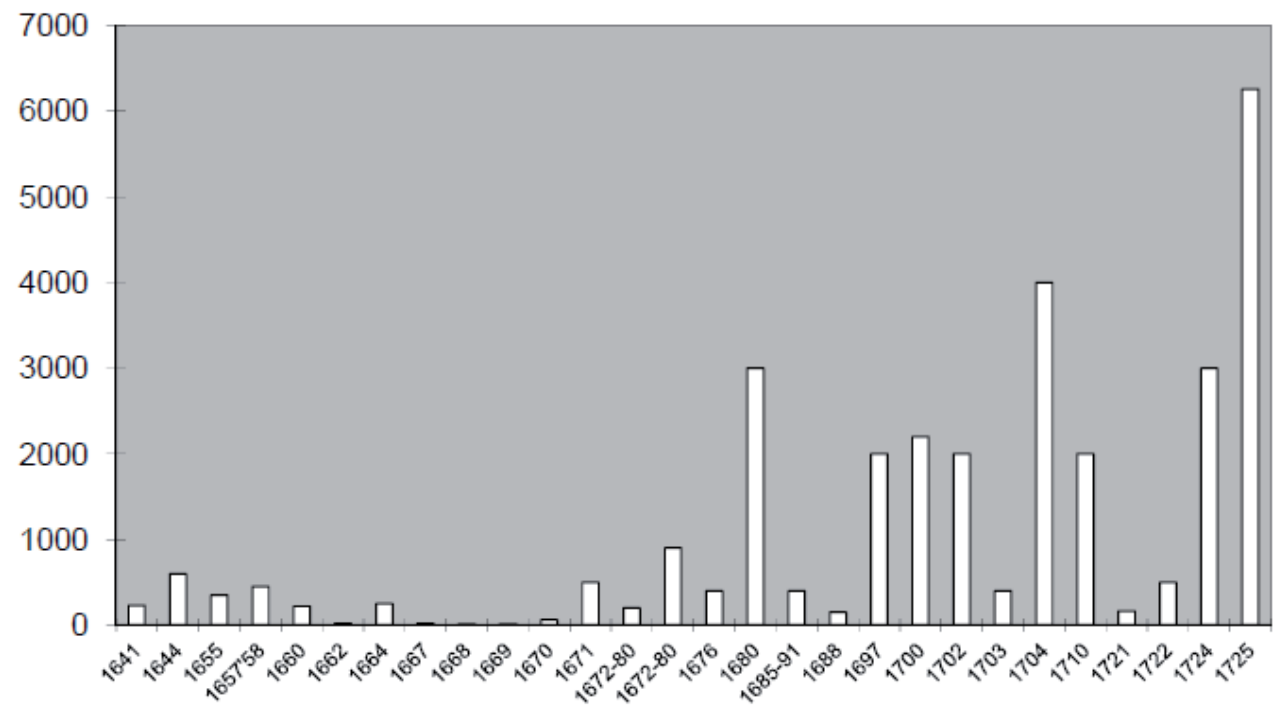

Gráfico 4 - Número de los soldados guaraníes enviados por año

Fuente: Francisco Burgés, Memorial al Rey Nuestro Señor en su Real y Supremo Consejo de las Indias sobre las noticias de las Misiones de los indios llamados chiquitos, y del estado que hoy tienen estas y las de los Rios Paraná, y Uruguay que están a cargo de los padres de la Compañía de Jesús, de la Provincia del Paraguay, [1702?]," RAH, Sección Jesuitas 9/3629, ff. 10v-12r; "Exposición al Rey del P. Jerónimo Herrán sobre las alteraciones y persecución de los jesuitas del Paraguay," primer tercio del siglo XVIII, RAH, Sección Jesuitas 9/3714, f. $4 \mathrm{r}-5 \mathrm{v}$.

\section{A modo de conclusión}

En este artículo hemos analizado la diferencia que existió y los cambios que ocurrieron en la relación entre el cacicazgo y la milicia de las reducciones jesuíticas a lo largo del tiempo. En la primera mitad del siglo XVII, los caciques con el título de Don dirigían sus vasallos y el modo de formar las milicias correspondía al cacicazgo, organización básica en la vida cotidiana. Por contraste, en la segunda mitad del siglo XVIII, las milicias estaban organizadas por un principio totalmente diferente: cada compañía estaba compuesta por 
50 soldados y los que no eran caciques ocupaban los puestos militares. Suponemos que este cambio fundamental de la organización militar se debió a la transformación de la función de las reducciones guaraníes para la Corona española, la que comenzó a experimentarse en 1641, culminando en 1680. El envío de 3.000 soldados para la primera ocupación de Colonia del Sacramento es un hecho decisivo el cambio de la organización militar de los guaraníes.

A partir de la contribución de este artículo podrían profundizarse en la futura investigación algunos temas. En primer lugar, la función de las milicias guaraníes en la acción de guerra. Aunque es claro que la estructura de la organización de las milicias guaraníes se basa en un principio fundamentalmente diferente del de cacicazgo, la manera de funcionamiento de esta nueva organización militar todavía no está clara. Las descripciones de numerosos informes y relaciones de los jesuitas para la Corona española estaban llenas de homenaje a la contribución militar de los guaraníes en diversos campos de batalla. No obstante, algunos diarios de los jesuitas en marcha militar nos muestran la existencia de algunos guaraníes indisciplinados a las órdenes de los misioneros ${ }^{14}$. Para profundizar esta cuestión, el análisis exhaustivo de los documentos relacionados con los guaraníes en la guerra es sumamente importante ¿En qué ocasión los guaraníes eran obedientes o desobedientes a los mandatos de los jesuitas y de los gobernadores españoles? La respuesta a esta cuestión es reflexionar sobre los alcances y las limitaciones de las milicias guaraníes en cada circunstancia.

En segundo lugar, puede profundizarse la comparación entre otras instituciones establecidas dentro del espacio misional. Este artículo se enfoca en el cambio de rol de los caciques guaraníes en el cacicazgo y en la milicia. Pero el análisis puede ampliarse al de los caciques en el cabildo y en las congregaciones o asociaciones religiosas del tipo cofradías, lo que resulta importante desde el punto de vista cronológico para entender el funcionamiento del liderazgo indígena en las misiones jesuíticas. Probablemente, las relaciones de cada organización serían interdependientes, siendo necesario comprender cada una en el conjunto. Este punto de vista global sería útil para aclarar la estructura fundamental de las misiones jesuíticas y la esencia de la política reduccional de la Corona española.

Por último, aunque no menos importante, cabe señalar un aspecto metodológico relacionado a las fuentes. En efecto, las fuentes principales utilizadas en este artículo son las listas de los nombres guaraníes elaboradas en varias ocasiones por los españoles o por los jesuitas. Creemos que el análisis

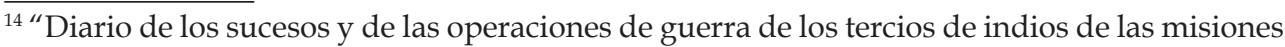
conducidas por los padres de la Compañía de Jesús, contra los indios infieles del Uruguay por el Padre Gerónimo Herrán, 1709," AGN VII, Colección Andrés Lamas, legajo n. 2609.

Tellus, ano 12, n. 23, jul./dez. 2012 
de este tipo de documentación podría complementar el resultado del más común estudio de las crónicas y se podría aplicar también al estudio de otros temas que contribuyan a una mejor comprensión de la historia de las misiones jesuíticas.

\section{Bibliografía}

\section{Manuscritos}

Archivo General de Indias (AGI), Sevilla, España.

Archivo General de la Nación (AGN), Buenos Aires, Argentina.

Biblioteca del Colegio Noviciado San Estanislao (BCNSE), Salamanca, España.

Biblioteca Nacional de España (BNE), Madrid, España.

Museo Mitre (MM), Buenos Aires, Argentina.

Real Academia de la Historia (RAH), Madrid, España.

\section{Documentos editados}

ANÓNIMO. Relación en que se da cuenta de las ciudades de la gobernación del Paraguay y de sus indios y del estado que tienen por el mes de diciembre de 1620 años en respuesta de lo que acerca de esto pregunto Su Majestad. In: CORTESÃO, Jaime (ed.). Jesuítas e bandeirantes no Guairá, (1549-1640). Rio de Janeiro: Biblioteca Nacional, 1951. (Manuscritos da coleção de Angelis, v. 1, p. 162-174).

BAZÁN DE PEDRAZA, Juan Gregorio. Padrones de los pueblos de indios guaraníes, hechos por el Maestre de Campo Don Juan Gregorio Bazán de Pedraza, Gobernador del Paraguay. In: PASTELLS, Pablo; MATEOS, Francisco (eds.). Historia de la Compañía de Jesús en la Provincia del Paraguay (Argentina, Paraguay, Uruguay, Perú, Bolivia y Brasil) según los documentos originales del Archivo General de Indias, v. 6 (1715-1731). Madrid: Consejo Superior de Investigaciones Científicas e Instituto Santo Toribio de Mogrovejo, 1946. p. 10-31.

CARDIEL, José. Breve Relación de las Misiones del Paraguay. In: HERNÁNDEZ, Pablo. Organización social de las doctrinas guaraníes de la Compañía de Jesús. Barcelona: Gustavo Gili, 1913. v. 2, p. 514-614.

Costumbres de los guaraníes. In: MURIEL, Domingo. Historia del Paraguay desde 1747 hasta 1767: obra latina del P. Domingo Muriel de la Compañía de Jesús, traducida al castellano por el P. Pablo Hernández de la misma Compañía. Madrid: Librería General Victoriano Suárez, 1918. p. 463-546.

. Carta y relación de las Misiones de la Provincia del Paraguay (1747). FURLONG, Guillermo (ed.) José Cardiel, S.J. y su carta-relación (1747). Buenos Aires: Librería del Plata, 1949. p. 115-213. 
. Compendio de la historia del Paraguay (1780). Buenos Aires: Fundación para la Educación, la Ciencia y la Cultura, 1984.

GUEVARA, José. Historia del Paraguay, Río de la Plata y Tucuman. In: ANGELIS, Pedro de (ed.) Colección de obras documentos relativos a la historia antigua y moderna de la Provincias del Río de la Plata, v. 1. Buenos Aires: Imprenta del Estado, 1836. p. 491-826.

JESUITAS. Breve suma de los caciques, que lo eran desde su gentilidad, contenidos en las peticiones y memoriales que dieron los padres doctrineros al visitador $\mathrm{D}$. Juan Blázquez de Valverde. In: PASTELLS, Pablo (ed.). Historia de la Compañía de Jesús en la Provincia del Paraguay (Argentina, Paraguay, Uruguay, Perú, Bolivia y Brasil) según los documentos originales del Archivo General de Indias, v. 2 (1638-1668). Madrid: Libraría General de Victoriano Suárez, 1915. p. 512-515.

LOZANO, Pedro. Historia de la Compañía de Jesús de la Provincia del Paraguay, v. 2. Madrid: Imprenta de la viuda de Manuel Fernández y del Supremo Consejo de la Inquisición, 1755.

MASTRILLI DURÁN, Nicolás. Carta Anua de 1626-1627. LEONHARDT, Carlos, RAVIGNANI, Emilio (eds.) Cartas Anuas de la Provincia del Paraguay, Chile y Tucumán, de la Compañía de Jesús, 1615-1637. Documentos para la historia argentina, v. 20. Buenos Aires: Talleres s.a. Casa Jacobo Peuser ltda., 1929.

SALÍNAS, María Laura (ed.). Liderazgos indígenas en las Misiones jesuíticas, títulos de capitanes concedidos a los caciques guaraníes en el siglo XVII. Folia Histórica del Nordeste, n. 16, p. 267-276, 2006.

SEPP, Antonio. Jardín de flores paracuario: edición crítica de las obras del padre Antonio Sepp, S. J., misionero en la Argentina desde 1691 hasta 1733, a cargo de Werner Hoffmann. Buenos Aires: Editorial Universitaria de Buenos Aires, 1974.

\section{Estudios}

AVELLANEDA, Mercedes. El ejercito guaraní en las reducciones jesuitas del Paraguay. História Unisinos, v. 9, n. 1, p. 19-34, 2005.

AVELLANEDA, Mercedes; QUARLERI, Lía. Las milicias guaraníes en el Paraguay y Río de la Plata: alcances y limitaciones (1649-1756). Estudos Ibero-Americanos, v. 33, n. 1, p. 109-132, 2007.

CARBONELL, Rafael. Estrategias de desarrollo rural en los pueblos guaranies (1609-1767). Barcelona: Antoni Bosch Editor, 1992.

CARVALLO, Casiano Néstor. Sintesis de historia de la Provincia de Misiones: contribución de los jesuitas a la formación histórica de Misiones. Posadas: Ediciones Montoya, 1980.

DÍAZ DE ZAPPIA, Sandra L. Participación indígena en el gobierno de las reducciones jesuíticas de guaraníes. Revista de Historia del Derecho, v. 31, p. 97-129, 2003.

JACKSON, Robert H. Demographic Patterns in the Jesut Missions of the Río de la Plata Region: The Case of Corpus Christi Mission, 1622-1802. Colonial Latin American Review, v. 13, n. 4, p. 337-366, 2004a.

Tellus, ano 12, n. 23, jul./dez. 2012 
. Una mirada a los patrones demográficos de las misiones jesuitas de Paraguay. Fronteras de la Historia, v. 9, p. 129-178, 2004 b.

The Post-Jesuit Expulsion Population of the Paraguay Missions, 1768-1803. Revista de História Regional, v. 13, n. 2, p. 134-169, 2008a.

. The Population and Vital Rates of the Jesuit Missions of Paraguay, 1700-1767. Journal of Interdisciplinary History, v. 38, n. 3, p. 401-431, 2008b.

JAEGER, Odilon. A liturgia nas reduções dos guaranis. Perspectiva teológica, n. 2, p. 203-216, 1971.

KERN, Arno. Missões: uma utopia política. Porto Alegre: Mercado Aberto, 1982.

MAEDER, Ernesto J. A. La población del Paraguay en 1799: el censo del gobernador Lazaro de Ribera. Estudios Paraguayos, v. 3, n. 1, p. 63-86, 1975.

. La población de las misiones de guaraníes (1641-1682): reubicación de los pueblos y consecuencias demográficas. Estudos Ibero-Americanos, v. 15, n. 1, p. 49-68, 1989.

MAEDER, Ernesto; BOLSI, Alfredo S. C. La población de las misiones guaraníes entre 1702-1767. Estudios Paraguayos, v. 2, n. 1, p. 111-137, 1974.

. Evolución y caracteristicas de la población guaraní de las Misiones Jesuíticas. Historiografía, v. 2, p. 113-150, 1976.

La población de las misiones de guaraníes después de la expulsión de los jesuitas. Faculdade de Filosofia, Ciência e Letras Dom Bosco. A população missioneira: fatores adversos e favoráveis às reduções (Anais do IV Simpósio Nacional de Estudos Missioneiros). Santa Rosa: Faculdade de Filosofia, Ciências e Letras Dom Bosco, 1983, p. 127-155.

MAEDER, Ernesto J. A.; LIVI-BACCI, Massimo. The Missions of Paraguay: The Demography of an Experiment. Journal of Interdisciplinary History, v. 35, n. 2, p. 185-224, 2004.

MÖRNER, Magnus. The Political and Economic Activities of the Jesuits in the La Plata Region: the Hapsburg Era. Stockholm: Library and Institute of Ibero-American Studies, 1953.

NECKER, Louis. Indios guaranies y chamanes franciscanos: las primeras reducciones del Paraguay (1580-1800). Asunción: CEAUAA, 1990.

ROULET, Florencia. Fragmentación política y conflictos interetnicos: las condiciones internas de la vulnerabilidad de los guaraní ante la conquista española. Suplemento Antropológico, v. 27, n. 1, p. 159-186, 1992.

. La resistencia de los guaraní del Paraguay a la conquista española (1537-1556). Posadas: Editorial Universitaria-UNM, 1993.

SUSNIK, Branislava 1966. Los trece pueblos guaranies de las Misiones. El indio colonial del Paraguay, v. 2. Asunción: MEAB, 1996.

. Apuntes de etnografía paraguaya, Asunción: Museo Etnográfico “Andrés Barbero," 1970 [1961]. 
Etnohistoria de los guaraníes: época colonial. Los abrígenes del Paraguay, v. 2. Asunción: Museo Etnográfico “Andrés Barbero,” 1979-1980.

SUSNIK, Branislava; CHASE-SARDI, Miguel. Los indios del Paraguay, Madrid: MAPFRE, 1992.

SVRIZ WUCHERER, Pedro M. O. Jesuitas, guaraníes y armas: milicias guaraníes frente a los indios del Gran Chaco. História Unisinos, v. 15, n. 2, p. 281-293, 2011a.

. El informe del Padre Provincial jesuita Jaime de Aguilar (1735): fuente para el estudio de las actividades de las milicias guaraníes en la gobernación del Paraguay. Folia Histórica del Nordeste, n. 19, p. 119-141, 2011 b.

Disputas a orillas del río Uruguay: guerra y paz con los minuanes en el siglo XVIII. Gazeta de Antropología, v. 27, n. 2, p. 1-17, 2011c.

WILDE, Guillermo. Prestigio indígena y nobleza peninsular: la invención de linajes guaraníes en las misiones del Paraguay. Jahrbuch für Geschichte Lateinamerikas, v. 43, p. 119-145, 2006.

. Religión y poder en las misiones de guaranies, Buenos Aires: SB, 2009.

Recebido em 12 de agosto de 2012

Aprovado para publicação em 15 de setembro de 2012 
